\title{
Therapies for Olfactory Dysfunction — an Update
}

\author{
Aria Jafari ${ }^{1}\left(\mathbb{0} \cdot\right.$ Eric H. Holbrook ${ }^{2}$
}

Accepted: 22 December 2021 / Published online: 24 January 2022

This is a U.S. government work and not under copyright protection in the U.S.; foreign copyright protection may apply 2022

\begin{abstract}
Purpose of Review Olfactory dysfunction is a prevalent condition affecting 5-15\% of the general population, with significant impact on quality of life. This review summarizes the most recent and relevant literature in the treatment of olfactory dysfunction.

Recent Findings Current evidence supports the short-term use of topical corticosteroids and systemic therapy. These treatments may occur in conjunction with olfactory training, which is well supported by the literature. While there are several additional treatments currently under investigation, meaningful conclusions are not yet able to be made regarding their efficacy. Summary The treatment of olfactory dysfunction is targeted at the suspected etiology when possible. After normal aging, chronic rhinosinusitis, post-infectious sequelae including as a result SARS-CoV-2 infection (COVID-19), and head trauma are the most common causes. Current evidence supports the short-term use of topical corticosteroids and systemic therapy. Several additional treatments are under investigation but recommendations for their use cannot currently be made.
\end{abstract}

Keywords Olfaction $\cdot$ Smell loss $\cdot$ Smell disorder $\cdot$ Olfaction disorder $\cdot$ Olfactory impairment $\cdot$ Anosmia

\section{Introduction}

A decrease in ones' ability to smell (i.e., olfactory loss) occurs in $5-15 \%$ of the population and is impactful on individuals' quality-of-life and safety [1,2]. Emerging associations of olfactory loss with neurodegenerative diseases (e.g., Parkinson disease) as well as incipient findings related to SARS-CoV-2 infection during the coronavirus disease 2019 (COVID-19) pandemic has further heighted public awareness of this prevalent condition.

As the therapeutic options are predicated on the etiology, determining the cause of olfactory dysfunction is integral to its management. Normal aging significantly contributes to the disease burden, with nearly half of adults ages $65-80$ experiencing olfactory impairment [3]. Not considering

This article is part of the Topical Collection on Rhinosinusitis

Aria Jafari

ajafari@uw.edu

1 Department of Otolaryngology-Head \& Neck Surgery, Division of Rhinology and Endoscopic Skull Base Surgery, University of Washington, Seattle, WA 98195-6515, USA

2 Department of Otolaryngology-Head \& Neck Surgery, Harvard Medical School, Massachusetts Eye and Ear, Boston, MA, USA aging, olfactory loss is most commonly caused by rhinosinusitis (either acute or chronic) [4]. Other etiologies include post-infectious sequelae from an upper respiratory tract infection (URTI) and SARS-CoV-2 infection (COVID-19) [5], head trauma [6], and other rarer conditions and exposures such as neurodegenerative disease [7], inhaled toxins, or medication side effects.

A treatment strategy which is directed toward the underlying etiology is more likely to be effective and can help address patient expectations for recovery. In addition to obtaining a thorough medical and rhinologic specific history with symptom onset and duration, attention should be given to possible neurologic causes (e.g., tremor suggesting Parkinson Disease; cognitive problems suggesting Alzheimer's disease) as well as medication use.

With many of these causes outside of chronic rhinosinusitis, treatment strategies have provided minimal benefits and proper identification of cause can help direct counseling on prognosis. In all cases, regardless of etiology or prognosis, patients need to understand the effect of olfactory loss on the ability to identify environmental hazards, such as smoke from a fire, natural gas leaks, or spoiled foods. As such, in patients with such loss, safety and risk mitigation strategies should be advised (e.g., smoke and gas alarms, electric appliances).

Despite the historic difficulty in providing therapies, there have been several meaningful advances in the ability to treat 
olfactory loss in the last decade. In this review, we will present and discuss the latest in therapeutics and offer treatment recommendations based on our experience treating patients with loss of smell.

\section{Treatment Options}

\section{Medical Therapies}

\section{Topical Corticosteroids}

Treatment with topical corticosteroids is commonly utilized by clinicians in the treatment of olfactory loss, irrespective of the etiology. The literature supportive of the use of topical corticosteroids is largely extrapolated from the treatment of CRS-related olfactory dysfunction $[8 \bullet \bullet, 9,10]$. Although studies showing benefit to olfaction from topical corticosteroids in non-CRS-related olfactory loss are limited, the risk for this intervention is low and may be considered as monotherapy or as an adjunct with other treatment (e.g., olfactory training) with appropriate patient counseling [11•].

\section{Systemic Corticosteroids}

Systemic corticosteroids can also be effective in treating olfactory loss in CRS with nasal polyps. The patient's response to this systemic treatment may also help distinguish an inflammatory etiology from other causes. The mechanism underlying the benefit is thought to be related to reduction of inflammatory mediators, but recent research has also shown that olfactory gene expression may also be influenced by this systemic therapy [12].

As the precise biological mechanism remains a topic of active research, several clinical studies have demonstrated benefit in olfaction after systemic corticosteroids using objective measures, beyond what would be expected from spontaneous recovery [13]. However, these studies are heterogeneous in etiology and often lack a control group, thereby limiting the generalizability. Additional studies have also sought to evaluate the potential additive effect of adjunctive treatments, particularly along with zinc in traumatic loss and with vitamin B supplementation $[14,15]$. These studies have demonstrated that there may be additive benefit to olfactory function using these additional treatments, beyond corticosteroid monotherapy alone.

Clinicians who elect to offer patients treatment with systemic corticosteroids should have a thorough discussion the potential adverse effects of this therapy given the lack of sound evidence. Additional studies are needed to better determine the effective dose and duration of this treatment as well as the interactive effects of adjunctive treatments.

\section{Biologics}

Biologics are an emerging treatment in CRS with nasal polyps and refer to a class of drugs that target the immune pathway underlies this inflammatory disease. These drugs consist of monoclonal antibodies which target the key effectors of type 2 inflammation. For example, omalizumab is a medication targeted against $\mathrm{IgE}$, a mast cell activator. Although this medication has been shown to be effective in decreasing polyp scores and improving quality of life, its impact on olfaction is not clear and only small studies exist. Pinto et al. conducted a study of 14 patients, 7 in each arm, where olfactory testing (UPSIT) did not show a significant difference between groups [16]. Similarly, mepolizumab (Anti IL-5) is designed to disrupt the maturation and recruitment of eosinophils; however, the effect of this medication on olfaction is not well studied. Dupilumab is a monoclonal antibody to the IL 4 receptor alpha subunit, which is shared with IL-13. This drug inhibits the cytokine signaling central to type 2-mediated inflammation. Bachert et al. demonstrated an improvement in olfaction (UPSIT) in the dupilumab group compared to controls following treatment [17]. Most recently, in a pooled analysis by Mullol et al., dupilumab was shown to provide a rapid and sustained improvement in olfaction, as measured by UPSIT [18]. Thus, dupilumab has the most evidence for improvement in olfaction in patients with CRS with nasal polyps to date.

\section{Intranasal Calcium Buffers}

As calcium ions within mucus may have an inhibitory role in olfactory signaling, calcium buffers (e.g., sodium citrate) have emerged as an intuitive method to treat olfactory loss. In recent years, Whitcroft and colleagues showed clinical improvement after a single topical administration of sodium citrate in patients with post-infectious smell loss, including a prospective single-blinded, placebo-controlled trial [19, 20]. This was followed by a subsequent double-blinded study evaluating this same treatment in a more diverse etiologic cohort [21]. Although the benefit was transient, it could provide patients with episodes of olfactory improvement during critical times such as during meals. This therapy has a compelling mechanistic basis and future clinical research could be helpful to discern the durability of benefit and range of benefit based on degree of olfactory loss.

\section{Phosphodiesterase Inhibitors}

Phosphodiesterase inhibitors (PDI) prevent the degradation of intracellular cyclic adenosine monophosphate (cAMP) and cyclic guanosine monophosphate (cGMP), thereby increasing levels of these molecules within olfactory epithelial cells. Theoretically, this would lead to a more 
efficient signal transduction cascade to the olfactory bulb. However, clinical results from PDI inhibitors (e.g., theophylline, sildenafil, caffeine, and pentoxifylline) have been mixed. Theophylline is the most widely studied PDI, with initial reports by Henkin et al. reported subjective improvement in approximately half of patients with olfactory loss with oral treatment, although a proper controlled study was lacking [22]. Given the potential for adverse systemic effects (e.g., restlessness, gastrointestinal discomfort, and sleep disturbance), topical intranasal administration was also studied and reported to be effective in some patients $[23,24]$.

The literature with regard to other PDIs, however, is less promising and raises questions regarding the presumed biological basis. For instance, a recent double-blind placebo-controlled study of a single administration of caffeine $(65 \mathrm{mg})$ had no effect on olfactory function, and similarly, a study of 6 patients with post-traumatic hyposmia treated with penoxifylline also showed no olfactory benefit $[25,26]$. Overall, the benefit for PDI treatment has yet to be established given the lack of control arm, etiologic heterogeneity, and data derived mostly from subjective assessments rather than validated instruments.

\section{Other}

Several other therapies have recently been investigated in the treatment of olfactory loss. Supplementation with alpha-lipoic acid, vitamin A, omega-3, and treatment with intranasal insulin has been studied with mixed results. The rationale for these treatments is their presumed neuroregenerative potential and anti-oxidant properties. Oral administration of alpha-lipoic acid (600 mg/day) was studied in 23 patients and approximately $60 \%$ experienced an improvement in olfaction on objective assessments [27]. Furthermore, in 2017, Hummel et al. found that those patients undergoing treatment with topical, intranasal vitamin A used in conjunction with olfactory training showed significant benefit to odor discrimination compared to those who did not [28]. Additionally, Yan et al. conducted a multiinstitutional, prospective, randomized controlled trial of 110 patients undergoing transsphenoidal surgery in 2019 and found that treatment with omega-3 demonstrated led to less persistent olfactory loss compared to controls [29]. Also, a pilot study of intranasal administration of insulin demonstrated improved odor sensitivity, and a more recent randomized-controlled trial improved odor identification and overall olfactory function among 38 patients with hyposmia $[30,31]$. Overall, the utility of these treatments is yet to be proven in larger trials with etiologic diversity in olfactory loss beyond spontaneous improvements, which can be up to $35 \%$ in some forms of smell loss [32].

\section{Procedural Interventions}

\section{Olfactory Training}

There is substantial evidence to suggest that olfactory training is effective in the treatment of olfactory loss. This treatment was first described by Hummel et al. in 2009 in a prospective controlled study of 24 patients with diverse etiologies for olfactory loss. In the described paradigm, patients underwent repeated exposures to four odors (i.e., rose, eucalyptus, clove, and lemon) twice daily for 3 months and olfactory function was assessed using Sniffin' Sticks [33]. There was significant benefit in olfactory function from this intervention.

The rationale for this treatment is thatrepetitive stimulation of the olfactory system could enhance regenerativecapacity and/or allow for proper neuron survival and targeting during recovery.Subsequent studies have elaborated on this paradigm, with variations on thetreatment duration, odor concentrations, and with change in odorants afterevery 3 months with some additional benefit. However, other groups havesuggested that the benefit from olfactory training may be similar to spontaneous recovery [34-37]. Further research would be helpful to determine the benefit of this intervention beyond that of spontaneous recovery and with more specific inclusion criteria (i.e., etiologic homogeneity) and standardized treatment durations. Based on the available current evidence, we routinely recommend olfactory training in symptomatic cases of olfactory loss which has been persistent, including following COVID-19 infection. The olfactory training paradigm adopted by the authors is included as Fig. 1.

Recent research has focused on the neurobiological basis of the effect and whether the effects are central (cortical) or at the level of the sensory epithelium. In 2018, Hummel et al. showed that electro-olfactogram (EOG) recordings from olfactory epithelium were higher in patients after OT, supporting the presumed effect on neuronal signaling and plasticity [38•]. More recently, Al Aïn et al. showed increased cortical thickness in olfactory processing areas of the brain after 6 weeks of olfactory training [39]. Further neuroimaging studies of patients with post-traumatic olfactory loss undergoing OT have suggested that the benefit in this group could be due to functional cortical changes rather than enhancements at the sensory epithelium [40, 41]. It is entirely possible that both central and peripheral processes are impacted by this intervention, but further studies are needed to better understand the underlying biological changes.

\section{Acupuncture}

Traditional Chinese Acupuncture (TCA) has been used for centuries as treatment for a variety of medical conditions. This technique was studied by Dai et al. in 50 patients with 
Fig. 1 Olfactory Training Paradigm, adopted by the authors (adapted from Altundag et al. [30]) Caption: A set of four odorants as described below are selected every three months for olfactory training. Each odorant is smelled for 15 seconds, with a 10 second rest between odorants. The set of odorants are smelled twice daily

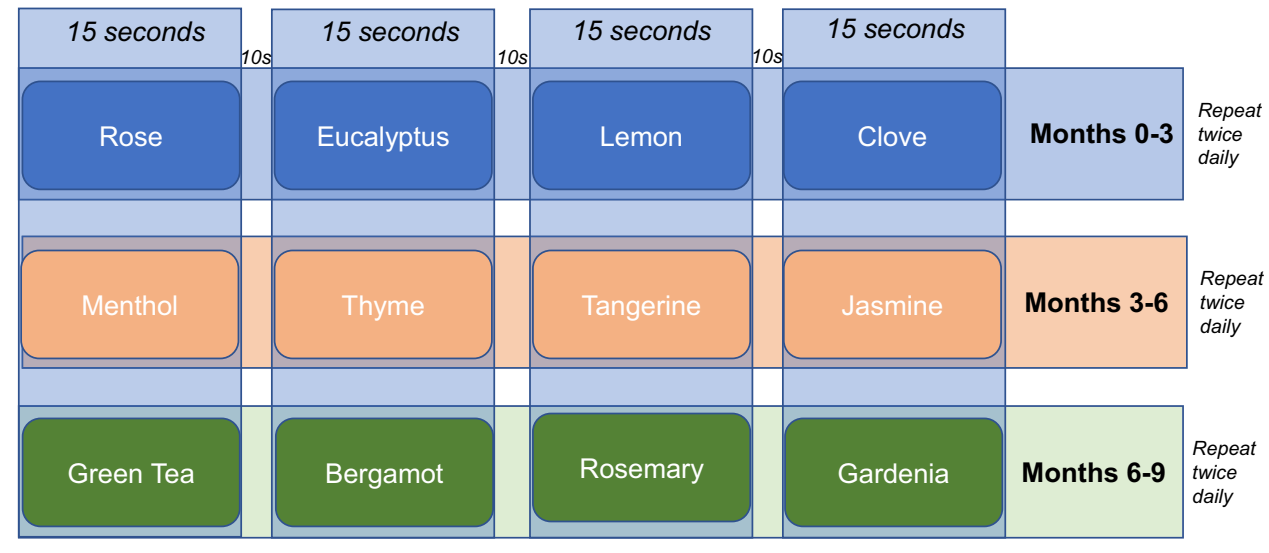

post-viral olfactory loss refractory to various conventional treatments (oral steroids, vitamin B, olfactory training, or intranasal steroids) [42]. After 3 months of three-times weekly TCA, 11 of 25 patients in the treatment group reported improved olfactory function of at least 4 points on the University of Pennsylvania Smell Identification Test, whereas 4 of 25 reported improvement in the no treatment group $(p=0.031)$. Similar to other interventions, patients with shorter symptom duration, and those with hyposmia rather than total smell loss tended to be more likely to improve. Another study of 15 patients with post-viral olfactory loss showed that those who underwent once-weekly TCA for 10 weeks were more likely to improve their olfactory function compared to those who received vitamin $\mathrm{B}$ (53.3\% vs. $13.3 \%$, respectively) [43].

\section{Surgery}

One of the cardinal symptoms of chronic rhinosinusitis is olfactory dysfunction and is present in a substantial portion of affected patients. The etiology of this dysfunction may be related to physical obstruction of odorants reaching the olfactory cleft (i.e., conductive loss) and/or inflammatory mediators affecting the functioning of the neuro-epithelium. There is considerable evidence that endoscopic sinus surgery benefits olfaction [44], presumably by controlling the underlying disease process through ventilation of the paranasal sinuses and facilitation of topical therapies. This improvement may be even more apparent and likely in patients who undergo concomitant septoplasty, have obstructive nasal polyps, and have more severe baseline olfactory dysfunction [45•]. This literature, however, is heterogenous in terms of the measures used to assess olfaction (i.e., subjective, odoridentification, or odor-threshold).

In addition to surgery for chronic rhinosinusitis, nasal surgery including septoplasty and septorhinoplasty has also been studied as interventions which may improve olfaction by facilitating airflow and topical delivery to the olfactory cleft. However, this data is mixed, with a recent study indicating that there are no beneficial effects while others have demonstrated favorable responses. The literature related to septorhinoplasty is more limited, but early results suggest a modest benefit to olfactory function $[46,47]$. It is important to note that these interventions also carry inherent risk for olfactory impairment due to iatrogentic injury related to trauma or scarring of the olfactory cleft, or surgical disruption of the olfactory system during endoscopic skull base surgery.

Occasionally, patients with olfactory disorders including significant parosmias or phantosmias unresponsive to medical therapies and with significant impact on quality of life may be considered for surgical removal of the olfactory epithelium. This has been shown in several small series to be effective in resolving phantosmia symptoms [48-50]. However, the risks associated with this intervention should be carefully considered against the potential benefits. Specifically, given that olfactory disturbances may be the sign of recovery and may improve with treatment. This procedure should be considered only after careful evaluation and selection by a surgeon with experience in olfactory disorders at a facility equipped to manage the possible complications (e.g., cerebrospinal fluid leak).

\section{Emerging Treatments}

Commensurate with advancements in our understanding of the biological basis of olfactory loss, novel therapeutic options have also recently emerged.

Researchers have recently studied the use of $\mathrm{N}$-acetylcysteine (100 mg/kg twice daily) after acute olfactory neuronal injury in animal models with promising results [51]. These researchers found a neuroprotective effect with this treatment, with significantly fewer olfactory neurons undergoing apoptosis in the group undergoing the treatment. Given the potential protective effects of this medication on a molecular level, there is some promise that this therapy could also provide clinical benefit to olfaction in humans, perhaps after head trauma.

The inherent regenerative capacity of the olfactory epithelium offers a compelling therapeutic target for treatment. 
Yan et al. recently reported the use of platelet-rich-plasma (PRP), which is derived from the patient's blood and with known pro-regenerative properties. Seven patients ( 2 with anosmia, 5 with hyposmia) with olfactory loss without signs of sinonasal inflammation recalcitrant to olfactory training and topical corticosteroids were included. Three of the patients with hyposmia achieved normosmia at 3-month follow-up [52]. Future studies are needed in a larger cohort with controls to determine the potential benefit of this intervention.

Metaplastic respiratory epithelial replacement and aneuronal degeneration can occur with various forms of olfactory loss. Therefore, activation or replacement of the stem cells typically responsible for the normal maintenance and repair of olfactory epithelium is another promising future therapeutic option [53, 54]. Kurtenbach et al. used this concept in a mouse model of hyposmia and showed improvement in function with nasal infusion of stem cells [55]. These methods may provide a future new era of treatment for those suffering smell loss related to disorders of the olfactory epithelium including post-viral causes, toxic exposure, and aging. However, more central causes would not be expected to benefit from this technique.

Electrical neurostimulation of the olfactory bulb or more central pathways provides another potential therapeutic intervention similar to other sensory systems such as hearing, balance, and vision [56, 57]. As a recent proof-of-concept study demonstrating the ability to electrically stimulate the olfactory bulb, three of five patients reported perception of smell with stimulation transnasally through the ethmoid sinus
[58••]. Further studies are underway with the ultimate goal toward an olfactory implant system, similar to other available electrical neurostimulatory devices to restore olfaction in patients with olfactory loss in the future.

\section{Conclusions}

Here, we present the recent literature regarding treatment of olfactory dysfunction. In our experience, determining the etiology of the condition by careful elicitation of history is paramount to determining an effective treatment strategy. A summary of the common causes and treatments for olfactory loss is shown in Fig. 2.

The current best evidence for treatment of one common type of olfactory loss, due to rhinosinusitis, remains systemic and/or topical corticosteroid therapy. An oral steroid taper can provide initial but typically temporary improvement in these patients if no further intervention is provided. The steroid taper can also help determine if the smell loss has reached a state of permanent loss after a prolonged inflammatory state. However, in most circumstances, an initial steroid taper allows for effective maintenance therapy through topical steroid rinses or inhaler devices. The decision to initiate systemic corticosteroid treatment should follow a thorough discussion of the rationale and the potential adverse effects. Endoscopic sinus surgery may be helpful in patients who do not respond adequately to appropriate medical therapy and also have additional symptoms consistent with chronic rhinosinusitis. Furthermore, newer systemic

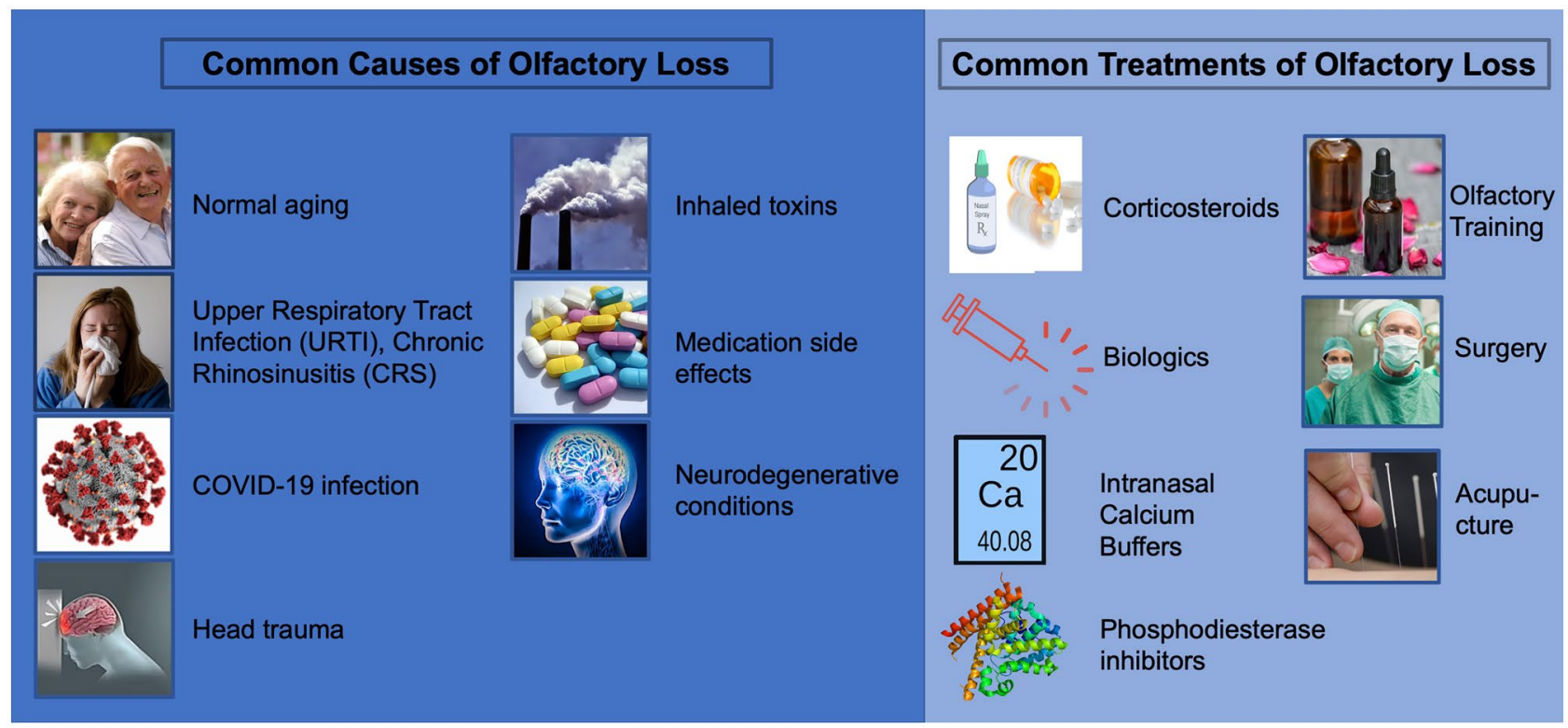

Fig. 2 Summary of common causes of olfactory loss and relevant treatments. Caption: Photo Credit: Creative Commons, attribution by unknown authors, CC-BY 
immune modulating drugs have also shown recent promise especially in recovery of olfactory function in patients with refractory polyp disease. Unfortunately for all other forms of smell loss unrelated to chronic rhinosinusitis, medical therapies are mostly unproven. Olfactory training remains a viable and safe treatment option for these patients with several studies showing benefit. Increased duration of treatment (i.e., greater than 3 months) and rotation of odorants (i.e., replacement of odorants after 3 months) may increase efficacy.

Emerging and adjunctive treatments do show some promise in patients who do not respond to the above therapies. Patients who have failed standard therapies may be presented with the option of enrolling in studies to pursue treatments that are yet available. Given the burgeoning scientific, clinical, and societal interests in olfactory loss and the treatments therein, especially in response to the recent COVID-19 pandemic, there will assuredly continue to be major advances in the treatment of this impactful condition in the coming years.

\section{Compliance with Ethical Standards}

Conflict of Interest None.

\section{References}

Papers of particular interest, published recently, have been highlighted as:

- Of importance

- Of major importance

1. Hummel T, Whitcroft KL, Andrews P, et al. Position paper on olfactory dysfunction. Rhinol Suppl. 2017;54(26):1-30. https:// doi.org/10.4193/Rhino16.248.

2. Nordin S, Brämerson A, Bende M. Prevalence of self-reported poor odor detection sensitivity: the Skövde population-based study. Acta Otolaryngol. 2004;124(10):1171-3. https://doi.org/ 10.1080/00016480410017468.

3. Murphy C, Schubert CR, Cruickshanks KJ, Klein BEK, Klein R, Nondahl DM. Prevalence of olfactory impairment in older adults. JAMA. 2002;288(18):2307-12. https://doi.org/10.1001/ jama.288.18.2307.

4. Jiang R-S, Lu F-J, Liang K-L, et al. Olfactory function in patients with chronic rhinosinusitis before and after functional endoscopic sinus surgery. Am J Rhinol. 2008;22(4):445-8. https:// doi.org/10.2500/ajr.2008.22.3195.

5. Mullol J, Alobid I, Mariño-Sánchez F, Izquierdo-Domínguez A, Marin C, Klimek L, Wang DY, Liu Z. The loss of smell and taste in the COVID-19 outbreak: a tale of many countries. Curr Allergy Asthma Rep. 2020;20(10):61. https://doi.org/10.1007/ s11882-020-00961-1.PMID:32748211;PMCID:PMC7397453.

6. Marin C, Langdon C, Alobid I, Mullol J. Olfactory dysfunction in traumatic brain injury: the role of neurogenesis. Curr Allergy Asthma Rep. 2020;20(10):55. https://doi.org/10.1007/s11882020-00949-x (PMID: 32648230).
7. Marin C, Vilas D, Langdon C, Alobid I, López-Chacón M, Haehner A, Hummel T, Mullol J. Olfactory dysfunction in neurodegenerative diseases. Curr Allergy Asthma Rep. 2018;18(8):42. https://doi.org/ 10.1007/s11882-018-0796-4 (PMID: 29904888).

8.• Chong LY, Head K, Hopkins C, Philpott C, Schilder AGM, Burton MJ. Intranasal steroids versus placebo or no intervention for chronic rhinosinusitis. Cochrane Database Syst Rev. 2016;4(4):CD011996. https://doi.org/10.1002/14651858.CD011 996.pub2. This is a review of $\mathbf{1 8}$ randomized controlled trials with 2738 participants with chronic rhinosinusitis treated with intranasal steroids. A moderate benefit was seen in sinonasal symptoms, including olfactory dysfunction after treatment.

9. Banglawala SM, Oyer SL, Lohia S, Psaltis AJ, Soler ZM, Schlosser RJ. Olfactory outcomes in chronic rhinosinusitis with nasal polyposis after medical treatments: a systematic review and meta-analysis. International Forum of Allergy and Rhinology. 2014;4(12):986-94. https://doi.org/10.1002/alr.21373.

10. Alobid I, Benítez P, Cardelús S, et al. Oral plus nasal corticosteroids improve smell, nasal congestion, and inflammation in sino-nasal polyposis. Laryngoscope. 2014;124(1):50-6. https:// doi.org/10.1002/lary.24330.

11. Nguyen TP, Patel ZM. Budesonide irrigation with olfactory training improves outcomes compared with olfactory training alone in patients with olfactory loss. International Forum of Allergy and Rhinology. 2018;8(9):977-81. https://doi.org/10. 1002/alr.22140.Thisisarandomizedcontrolledtrialof133patients witholfactorylosstreatedeitherwithbudesonideorsalineirrigati oninadditiontoolfactorytraining.Addingbudesonideirrigationtool factorytrainingsignificantlyimprovedolfactoryability.

12. Tian J, Pinto JM, Xin Y, et al. Dexamethasone affects mouse olfactory mucosa gene expression and attenuates genes related to neurite outgrowth. International Forum of Allergy and Rhinology. 2015;5(10):907-18. https://doi.org/10.1002/alr.21586.

13. Schriever VA, Merkonidis C, Gupta N, Hummel C, Hummel T. Treatment of smell loss with systemic methylprednisolone. Rhinology. 2012;50(3):284-9. https://doi.org/10.4193/Rhino11. 207.

14. Jiang R-S, Twu C-W, Liang K-L. Medical treatment of traumatic anosmia. Otolaryngol Head Neck Surg. 2015;152(5):954-8. https://doi.org/10.1177/0194599815571272.

15. Heilmann S, Just T, Göktas O, Hauswald B, Hüttenbrink KB, Hummel T. Effects of systemic or topical administration of corticosteroids and vitamin B in patients with olfactory loss. Laryngorhinootologie. 2004;83(11):729-34. https://doi.org/10. 1055/s-2004-825676.

16. Pinto JM, Mehta N, DiTineo M, Wang J, Baroody FM, Naclerio RM. A randomized, double-blind, placebo-controlled trial of anti-IgE for chronic rhinosinusitis. Rhinology. 2010;48(3):31824. https://doi.org/10.4193/Rhino09.144 (PMID: 21038023).

17. Bachert C, Han JK, Desrosiers M, Hellings PW, Amin N, Lee SE, Mullol J, Greos LS, Bosso JV, Laidlaw TM, Cervin AU, Maspero JF, Hopkins C, Olze H, Canonica GW, Paggiaro P, Cho SH, Fokkens WJ, Fujieda S, Zhang M, Lu X, Fan C, Draikiwicz S, Kamat SA, Khan A, Pirozzi G, Patel N, Graham NMH, Ruddy M, Staudinger H, Weinreich D, Stahl N, Yancopoulos GD, Mannent LP. Efficacy and safety of dupilumab in patients with severe chronic rhinosinusitis with nasal polyps (LIBERTY NP SINUS24 and LIBERTY NP SINUS-52): results from two multicentre, randomised, double-blind, placebo-controlled, parallel-group phase 3 trials. Lancet. 2019;394(10209):1638-1650. https://doi. org/10.1016/S0140-6736(19)31881-1. Epub 2019 Sep 19. Erratum in: Lancet. 2019 Nov 2;394(10209):1618. PMID: 31543428.

18. Mullol J, Bachert C, Amin N, Desrosiers M, Hellings PW, Han JK, Jankowski R, Vodicka J, Gevaert P, Daizadeh N, Khan AH, Kamat S, Patel N, Graham NMH, Ruddy M, Staudinger H, 
Mannent LP. Olfactory outcomes with dupilumab in chronic rhinosinusitis with nasal polyps. J Allergy Clin Immunol Pract. 2021;S2213-2198(21)01104-1. https://doi.org/10.1016/j.jaip. 2021.09.037. Epub ahead of print. PMID: 34628065.

19. Whitcroft KL, Merkonidis C, Cuevas M, Haehner A, Philpott C, Hummel T. Intranasal sodium citrate solution improves olfaction in post-viral hyposmia. Rhinology. 2016;54(4):36874. https://doi.org/10.4193/Rhino16.054.

20. Whitcroft KL, Ezzat M, Cuevas M, Andrews P, Hummel T. The effect of intranasal sodium citrate on olfaction in postinfectious loss: results from a prospective, placebo-controlled trial in 49 patients. Clin Otolaryngol. 2017;42(3):557-63. https://doi.org/10.1111/coa.12789.

21. Philpott CM, Erskine SE, Clark A, et al. A randomised controlled trial of sodium citrate spray for non-conductive olfactory disorders. Clin Otolaryngol. 2017;42(6):1295-302. https://doi.org/10.1111/coa.12878.

22. Henkin RI, Velicu I, Schmidt L. An open-label controlled trial of theophylline for treatment of patients with hyposmia. Am J Med Sci. 2009;337(6):396-406. https://doi.org/10.1097/MAJ. 0b013e3181914a97.

23. Henkin RI, Schultz M, Minnick-Poppe L. Intranasal theophylline treatment of hyposmia and hypogeusia: a pilot study. Arch Otolaryngol Head Neck Surg. 2012;138(11):1064-70. https:// doi.org/10.1001/2013.jamaoto.342.

24. Nigwekar SU, Weiser JM, Kalim S, et al. Characterization and correction of olfactory deficits in kidney disease. J Am Soc Nephrol. 2017;28(11):3395-403. https://doi.org/10.1681/ ASN.2016121308.

25. Meusel T, Albinus J, Welge-Luessen A, Hähner A, Hummel T. Short-term effect of caffeine on olfactory function in hyposmic patients. Eur Arch Otorhinolaryngol. 2016;273(8):2091-5. https://doi.org/10.1007/s00405-015-3879-z.

26. Whitcroft KL, Gudziol V, Hummel T. Short-course pentoxifylline is not effective in post-traumatic smell loss: a pilot study. Ear Nose Throat J. 2020;99(1):58-61. https://doi.org/10.1177/ 0145561319840888.

27. Hummel T, Heilmann S, Hüttenbriuk K-B. Lipoic acid in the treatment of smell dysfunction following viral infection of the upper respiratory tract. Laryngoscope. 2002;112(11):2076-80. https://doi.org/10.1097/00005537-200211000-00031.

28. Hummel T, Whitcroft KL, Rueter G, Haehner A. Intranasal vitamin A is beneficial in post-infectious olfactory loss. Eur Arch Otorhinolaryngol. 2017;274(7):2819-25. https://doi.org/ 10.1007/s00405-017-4576-x.

29. Yan $\mathrm{CH}$, Rathor A, Krook K, et al. Effect of omega-3 supplementation in patients with smell dysfunction following endoscopic sellar and parasellar tumor resection: a multicenter prospective randomized controlled trial. Neurosurgery. 2020;87(2):E91-8. https://doi.org/10.1093/neuros/nyz559.

30. Schöpf V, Kollndorfer K, Pollak M, Mueller CA, Freiherr $\mathrm{J}$. Intranasal insulin influences the olfactory performance of patients with smell loss, dependent on the body mass index: a pilot study. Rhinology. 2015;53(4):371-8. https://doi.org/10. 4193/Rhino15.065.

31. Rezaeian A. Effect of intranasal insulin on olfactory recovery in patients with hyposmia: a randomized clinical trial. Otolaryngol Head Neck Surg. 2018;158(6):1134-9. https://doi.org/10.1177/ 0194599818764624

32. Hendriks AP. Olfactory dysfunction. Rhinology. 1988;26(4):229-51.

33. Hummel T, Rissom K, Reden J, Hähner A, Weidenbecher M, Hüttenbrink K-B. Effects of olfactory training in patients with olfactory loss. Laryngoscope. 2009;119(3):496-9. https://doi. org/10.1002/lary.20101.

34. Konstantinidis I, Tsakiropoulou E, Constantinidis J. Long term effects of olfactory training in patients with post-infectious olfactory loss. Rhinology. 2016;54(2):170-5. https://doi.org/ 10.4193/Rhin15.264.

35. Damm M, Pikart LK, Reimann $\mathrm{H}$, et al. Olfactory training is helpful in postinfectious olfactory loss: a randomized, controlled, multicenter study. Laryngoscope. 2014;124(4):826-31. https://doi.org/10.1002/lary.24340.

36. Altundag A, Cayonu M, Kayabasoglu G, et al. Modified olfactory training in patients with postinfectious olfactory loss. Laryngoscope. 2015;125(8):1763-6. https://doi.org/10.1002/ lary. 25245 .

37. Fornazieri MA, Garcia ECD, Lopes NMD, et al. Adherence and efficacy of olfactory training as a treatment for persistent olfactory loss. Am J Rhinol Allergy. 2020;34(2):238-48. https://doi. org/10.1177/1945892419887895.

38. Hummel T, Stupka G, Haehner A, Poletti SC. Olfactory training changes electrophysiological responses at the level of the olfactory epithelium. Rhinology. 2018;56(4):330-335. https://doi.org/ $10.4193 /$ Rhin 17.163 . This is a prospective case-control study of 27 healthy participants and 38 patients $(12$ ansomic/23 hyposmic). Electro-olfactogram responses were higher in patients after olfactory training, suggesting stimulus-induced plasticity.

39. Aïn Al S, Poupon D, Hétu S, Mercier N, Steffener J, Frasnelli J. Smell training improves olfactory function and alters brain structure. Neuroimage. 2019;189:45-54. https://doi.org/10. 1016/j.neuroimage.2019.01.008.

40. Pellegrino R, Han P, Reither N, Hummel T. Effectiveness of olfactory training on different severities of posttraumatic loss of smell. Laryngoscope. 2019;129(8):1737-43. https://doi.org/10. 1002/lary.27832.

41. Langdon C, Lehrer E, Berenguer J, Laxe S, Alobid I, Quintó L, Mariño-Sánchez F, Bernabeu M, Marin C, Mullol J. Olfactory training in post-traumatic smell impairment: mild improvement in threshold performances: results from a randomized controlled trial. J Neurotrauma. 2018;35(22):2641-52. https://doi.org/10. 1089/neu.2017.5230 (Epub 23 Jul 2018. PMID: 29790420).

42. Dai Q, Pang Z, Yu H. Recovery of olfactory function in postviral olfactory dysfunction patients after acupuncture treatment. Evid Based Complement Alternat Med. 2016;2016:4986034. https:// doi.org/10.1155/2016/4986034.

43. Vent J, Wang D-W, Damm M. Effects of traditional Chinese acupuncture in post-viral olfactory dysfunction. Otolaryngol Head Neck Surg. 2010;142(4):505-9. https://doi.org/10.1016/j.otohns. 2010.01.012.

44. Seys SF, De Bont S, Fokkens WJ, Bachert C, Alobid I, BernalSprekelsen M, Bjermer L, Callebaut I, Cardell LO, Carrie S, Castelnuovo P, Cathcart R, Constantinidis J, Cools L, Cornet M, Clement G, Cox T, Delsupehe L, Correia-de-Sousa J, Deneyer L, De Vos G, Diamant Z, Doulaptsi M, Gane S, Gevaert P, Hopkins C, Hox V, Hummel T, Hosemann W, Jacobs R, Jorissen M, Kjeldsen A, Landis BN, Lemmens W, Leunig A, Lund V, Mariën G, Mullol J, Onerci M, Palkonen S, Proano I, Prokopakis E, Ryan D, Riechelmann H, Sahlstrand-Johnson P, Salmi-Toppila S, Segboer C, Speleman K, Steinsvik A, Surda P, Tomazic PV, Vanderveken O, Van Gerven L, Van Zele T, Verfaillie J, Verhaeghe B, Vierstraete K, Vlaminck S, Wagenmann M, Pugin B, Hellings PW. Real-life assessment of chronic rhinosinusitis patients using mobile technology: the mySinusitisCoach project by EUFOREA. Allergy. 2020 Nov;75(11):2867-2878. https://doi.org/10.1111/all.14408. Epub 19 Jun 2020. PMID: 32424899; PMCID: PMC7687134.

45. Mattos JL. Mechanisms and treatment of olfactory dysfunction in chronic rhinosinusitis. Ann Allergy Asthma Immunol. 2020;124(4):307-308. https://doi.org/10.1016/j.anai.2020.01. 014 . This is a review of the mechanism and treatment of olfactory dysfunction in chronic rhinosinusitis. The author discusses that inflammation of the olfactory cleft epithelium 
leads to decreased odorant transport across the mucus layer, olfactory neurotoxicity, and impaired neuroregeneration.

46. Kokubo LCP, Carvalho TBO, Fornazieri MA, Gomes EM de C, Alves CMF, Sampaio ALL. Effects of septorhinoplasty on smell perception. Eur Arch Otorhinolaryngol. 2019;276(4):12471250. https://doi.org/10.1007/s00405-019-05356-1.

47. Randhawa PS, Watson N, Lechner M, Ritchie L, Choudhury N, Andrews PJ. The outcome of septorhinoplasty surgery on olfactory function. Clin Otolaryngol. 2016;41(1):15-20. https://doi. org/10.1111/coa.12463.

48. Morrissey DK, Pratap U, Brown C, Wormald PJ. The role of surgery in the management of phantosmia. Laryngoscope. 2016;126(3):575-8. https://doi.org/10.1002/lary.25647.

49. Leopold DA, Loehrl TA, Schwob JE. Long-term follow-up of surgically treated phantosmia. Arch Otolaryngol Head Neck Surg. 2002;128(6):642-7. https://doi.org/10.1001/archotol.128.6.642.

50. Leopold DA, Schwob JE, Youngentob SL, Hornung DE, Wright HN, Mozell MM. Successful treatment of phantosmia with preservation of olfaction. Arch Otolaryngol Head Neck Surg. 1991;117(12):1402-6. https://doi.org/10.1001/archotol.1991.01870240094016.

51. Goncalves S, GOLDSTEIN BJ. Acute N-acetylcysteine administration ameliorates loss of olfactory neurons following experimental injury in vivo. Anat Rec (Hoboken). 2020;303(3):626633. https://doi.org/10.1002/ar.24066.

52. Yan CH, Mundy DC, Patel ZM. The use of platelet-rich plasma in treatment of olfactory dysfunction: a pilot study. Laryngoscope Investig Otolaryngol. 2020;5(2):187-93. https://doi.org/ 10.1002/lio2.357.

53. GOLDSTEIN BJ, Goss GM, Choi R, et al. Contribution of polycomb group proteins to olfactory basal stem cell self-renewal in a novel c-KIT+ culture model and in vivo. Development. 2016;143(23):4394-4404. https://doi.org/10.1242/dev.142653.

54. Peterson J, Lin B, Barrios-Camacho CM, et al. Activating a reserve neural stem cell population in vitro enables engraftment and multipotency after transplantation. Stem Cell Reports. 2019;12(4):680 95. https://doi.org/10.1016/j.stemcr.2019.02.014.

55. Kurtenbach S, Goss GM, Goncalves S, et al. Cell-based therapy restores olfactory function in an inducible model of hyposmia. Stem Cell Reports. 2019;12(6):1354-65. https://doi.org/10. 1016/j.stemcr.2019.05.001.

56. Coelho DH, Socolovsky LD, Costanzo RM. Activation of the rat olfactory bulb by direct ventral stimulation after nerve transection. International Forum of Allergy and Rhinology. 2018;8(8):922-7. https://doi.org/10.1002/alr.22133.

57. Holbrook EH, Coelho DH. Cranial nerve stimulation for olfaction (cranial nerve 1). Otolaryngol Clin North Am. 2020;53(1):73-85. https://doi.org/10.1016/j.otc.2019.09.014.

58.• Holbrook EH, Puram SV, See RB, Tripp AG, Nair DG. Induction of smell through transethmoid electrical stimulation of the olfactory bulb. International Forum of Allergy and Rhinology. 2019;9(2):158-164. https://doi.org/10.1002/alr.22237. This is a proof-of-concept study of 5 patients who experienced induced smell through transethmoid electrical stimulation of the olfactory bulb. The results, which are the first of their kind, support the concept of development of an olfactory implant system in humans.

Publisher's Note Springer Nature remains neutral with regard to jurisdictional claims in published maps and institutional affiliations. 